\title{
COVID-19 SOCIAL DISTANCING AND PROFIT MAXIMIZATION INVENTORY MODEL WITH OVERAGE
}

\author{
Nivetha Martin ${ }^{1}$, A.Aleeswari ${ }^{2}$,P.Pandiammal ${ }^{3}$, N.Ramila Gandhi ${ }^{4}$ \\ ${ }^{1}$ Department of Mathematics, Arul Anandar College (Autonomous), Karumathur \\ ${ }^{2}$ Department of MBA, PSNA CET, Dindigul \\ ${ }^{3}$ Department of Mathematics, GTN Arts College (Autonomous), Dindigul \\ ${ }^{4}$ Department of Mathematics, PSNA CET, Dindigul
}

\begin{abstract}
Goal: This research work aims in presenting the impacts of social distancing on the societal domain in particularly with the special focus on inventory management, the accelerating fuel of the production sectors. A profit maximization inventory model comprises of overage management, waste disposal and product propagation is proposed.

Design / Methodology / Approach: A mathematical model with the objective of profit maximization and overage management is developed to cater the needs of the production sectors at times of pandemic situation.

Results: This model yields the optimal quantity $(\mathrm{Q \alpha})$ that maximizes the expected aggregate profit per unit of time.

Limitations of the investigation: This research is of exploratory kind and the lack of similar research in the literature locks the opportunity of comparison, also the proposed model is a more generalized in nature.

Practical implications: The proposed maximization model will certainly assist the decision makers to handle the situations of overage caused by pandemic social distancing. Originality/Value: The combination of profit maximization, overage management in the context of COVID 19 social distancing is modelled to benefit the production sectors and this is the novel approach of this article.
\end{abstract}

Keyword: COVID-19, Inventory Management, Production sectors, Social Distancing.

\section{Introduction}

The journey of human from Stone Age to this technology era has made him profoundly civilized and modernized. The humanity had circled them into the spin of advanced devices to get refreshed and tuned to the contemporary patterns. The manufacturing realm is made to go through extraordinary changes by the execution of cutting-edge creation innovation with technically sound incorporated strategies. The production sectors are going into the $\mathrm{E}$ world and this new symbol is acquiring extraordinary push (Deshmukh 2020). The thought process of consolidating such dynamic changes by the production firms is to encourage the pace of production and to make the progression of creation consistent with no interference. However, logically, inner and outside authoritative components recesses, which are very inescapable. The strength of hierarchical atmosphere on creation measures additionally wins and adds to the stoppage. To deal with such regular emergency, the mechanical divisions utilize worldwide and explicit procedures and figure reasonable strategies, in the event that the scrape reaches out past the outskirts of control, at that point the organization closes down. The production is stopped; the movement of items is delayed, crude materials never transformed into items. These are the results of manufacturing plant terminations. On the off chance that an organization that produces one sort of item is shut for not many days may upset the normal existence of the individuals and the general public somewhat, envision if a country chooses for LOCK DOWN, the outcomes are boundless (Naveen 2020). The assets will be depleted and destroyed at last. Right? Think about the cutting -edge status of our public economy, which the modern parts are making a decent attempt to support. It is very incredible.

Why a developing country like India calls for Social Distancing? For what reason to force Lock Down? Why such isolate? The appropriate response is to oppose and crush the impact of infinitesimal infection CORONA infection (Yan 2019), the current danger to the world, which shows no distinction to the countries it enters. A definitive assignment of this infection is mass mortality. It has its beginning in China and now it governs the world. The economy of the powerful countries is in the contracting stage and numerous countries are losing its personality, the HR are getting depleted. Will the world be thrashing this fate? The pioneers of the world are providing the main medication to this COVID-19; the existence sucker is Social Distancing (Unhale et al 2020). The Italians who overlooked this medication are in the midst of the urgent fight among life and passing. The waterway of torments is as yet streaming over this country. We are walking ahead with the expectation that this pandemic circumstance will likewise cruise by. 
Individuals, in the wake of understanding the need of social removing have begun to hold hands with their legislatures, yet at the same time some are yet to participate in this insubordination. Social distancing is simply the aggregate impact of each being far off from outside condition and this is surely difficult to rehearse by us, as we are being the aspect of this bustling universe for a very long while. Production sectors inspite of installing innovative production machinery require the participation of the human resources to operate and monitor the production process along with the supervision and exercising control over the inventory to avoid shortages. But if lock down enters into the picture, the production process gets deterred and the inventory levels left unsupervised. Every production firm maintains several levels of inventory of items for suppose let us consider, inventory of raw material, semifinished products and finished products (Poudel 2020). Since the probability of transportation of these kinds of products is very less, stagnation takes place. The minimum level of inventory gets accumulated by these new entrants. Now the problem is, if the situation gets resumed, then the inventory replenishment pattern gets affected. The inventory stock at hand gets accrued if the same fashion of inventory renewal is followed or the inventory decision makers may change the pattern after estimating the needed inventory level to be ordered with the consideration of the existing additional inventory at hand. There lies a difficulty in the later decision by the managerial people; it is the question of quality of the inventory. The mixture of inventory with varied degrees of quality collapses the production climate. The best solution to avert such quality hindrance situations is to follow the usual inventory renewal pattern. But what to do with the excess is the next immediate question (Kumar 2020).

Industries are well versed in handling the situations of shortage, the condition of deficit by employing the stratagem of backlogs. But, how the scenario of excess inventory should be defined and how the situation has to be modelled. This type of circumstances is also not new to the businessmen. The word 'Overage' aptly describes it and Geoff Relf (2013) was the person who made so. In his research article on Overage inventory, he has presented the factors contributing to its occurrence and stated that the overage inventory has certain positive impacts on proper supervision. Based on this conception, an inventory model focussing on overage management and customer acquisition was developed to tackle the excess levels of inventory. The model was so compatible and it was extended to fuzzy model by Ritha et al (2019).These models were concentrating on the inventory of single item, but if the multi items are taken into consideration then this overage inventory model of single item gets extended to overage inventory management model of multi items. This research work proposes an inventory model to encounter the mishaps in inventory management caused by COVID-19 social distancing.
Economic order quantity model was first developed by Harris (1913) and production inventory model was developed by Taft (1915). These two models are the building blocks of the inventory models. Inventory models assist in the continuous flow of the production processes and these models are modified to accommodate various challenges of inventory management. Inventory models comprising of shortage costs .partial and complete backlogging, price break up, trade discount, deteriorating items, supply chain management, integrated vendor and buyer models, environmental sustainability were modelled to meet out the challenges separately or simultaneously. The shortage inventory models are many in number and it has been combined with other challenges of inventory management. Swati et al (2013) developed an inventory model with deteriorating items, ramptype demand and partially backlogged shortages for a two warehouse system. Elham Ahmadzadeh et al (2017) developed a shortage inventory model in a closed loop supply chain network with correlated demands under a periodic review system. Alejandro et al (2017) developed an inventory model with supplier selection, inventory shortage, and quantity discounts. Umakanta Mishra et al (2020) constructed a sustainable production-inventory model for a controllable carbon emissions rate under shortages. But the models related to overage are not much focussed and so this research work throws light on the condition of overage inventory of multi items with special focus at times of this pandemic outbreak. This profit maximization inventory model comprises of overage management, waste disposal and product propagation. The article is structured as follows: section 2 presents the COVID - 19 inventory crisis combating model; section 3 comprises of validation of the proposed model; section 4 consists of the discussions based on the proposed model and the last section concludes the work.

\section{Design of COVID-19 Inventory Crisis Combating model}

The proposed model is the extension of the model based on overage management and customer acquisition .This model considers the inventory level of multi items with the aim of restoring the overage to maximum stock level. The quantity of items that makes the maximum inventory level reaches overage is defined as special inventory in the earlier proposed model. Let us consider the existing situation, the production sectors have been functioning with their inventory levels before the spread of COVID 19, suddenly after the spread of this infectious disease, the nation announces Lock down and people have started to follow the social distancing. The employees are quarantined. The time a company shuts down say at time $t$ has inventory levels of three items say $\mathrm{X}, \mathrm{Y}$ and $Z$. If the situation gets resumed at time $t_{1}$, then the routine activities of the company take place and it begins with ordering, producing and marketing. Let us assume that the three items are the inputs (raw material or semi-finished products) for producing the final product. The quality of three 
items depends on the time interval $t_{1}-t$. If $t_{1}-t \leq t^{*}$ then the condition of overage can be averted by following different inventory ordering policy. ( $\mathrm{t}^{*}$,the stipulated time of quality assurance of the items with the assumption that these inputs are uniform in its physical characteristics) If $t_{1}-t \geq t^{*}$, then inventory replenishment pattern is not changed, overage takes place.

The assumptions and the notations of the earlier model are incorporated into this model with certain changes. The concept of waste disposal is integrated with this multi item overage inventory model to make it more socially responsible inventory model. In the earlier model the inventory level gets raised to overage by a percentage $\mathrm{p}$ due to the accumulation of the inventory of the preceding cycle in the successor cycle, but here the presence of inventory at hand turns to be fruitful the situation is not causing any sort of commotions in inventory management, but if it fails, then the problem gets commenced. The inventory decision makers have to start their production process with the weeded on hand inventory and the newly arrived inventory in the production cycle. The former contributes to overage and the latter to the maximum stock level. With this problem description, the following inventory model is put forward in a more generalized manner, here $\alpha$ represents the items $\mathrm{X}, \mathrm{Y}$ and $\mathrm{Z}$.

Notations

$\mathrm{Q}_{\alpha} \quad$ order size of the items

$\mathrm{D}_{\alpha} \quad$ demand per unit time of the items

$\mathrm{p}_{\alpha} \quad$ percentage of items in $\mathrm{Q}_{\alpha}$ that adds to overage in the next cycle.

$\mathrm{f}\left(\mathrm{p}_{\alpha}\right) \quad$ probability density function of $\mathrm{p}_{\alpha}$

$\mathrm{K}_{\alpha} \quad$ fixed cost of placing an order

$\mathrm{h}_{\alpha} \quad$ holding cost per unit per unit of time in the maximum stock

$\mathrm{h}_{0 \alpha} \quad$ holding cost per unit of time in the special

inventory

$\mathrm{s}_{\alpha} \quad$ unit selling price of items in maximum stock

$\mathrm{v}_{\alpha} \quad$ unit selling price of items in overage, $\mathrm{v}_{\alpha}<\mathrm{s}_{\alpha}$

$r_{\alpha} \quad$ renovating cost per unit of an overage item

$\mathrm{w}_{\alpha} \quad$ weeding cost of the overage items

$\mathrm{d}_{\alpha} \quad$ waste disposal cost of the items

$\mathrm{j}_{\alpha} \quad$ percentage of overage times that are subjected

to disposal.

$\mathrm{f}\left(\mathrm{j}_{\alpha}\right) \quad$ probability density function of $\mathrm{j}_{\alpha}$

$\mathrm{P}_{\alpha} \quad$ Product propagation cost
T cycle length

The notations of the earlier model are presented in a comprehensive way to accommodate the costs associated with restoring overages to maximum stock level for multi items. One of the underlying assumptions in this proposed model is, the items are partially deteriorating in nature, where as in the former model the items are not of deteriorating type. The waste disposal costs are included and the costs subjected to customer acquisition are ignored as product propagation will reach maximum customers in high magnitude.

The aggregate income and expense per cycle is denoted by $\operatorname{TR}\left(Q_{\alpha}\right)$ and $\mathrm{TC}\left(\mathrm{Q}_{\alpha}\right)$ and $\operatorname{TRU}\left(\mathrm{Q}_{\alpha}\right)$ and $\mathrm{TCU}\left(\mathrm{Q}_{\alpha}\right)$ represents the aggregate income and expense per unit of time.

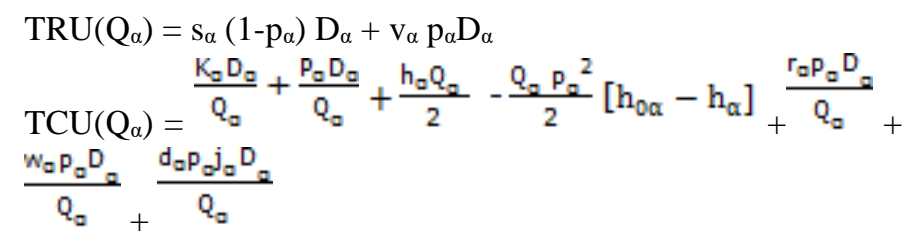

The total profit per unit time TPU(Q) is

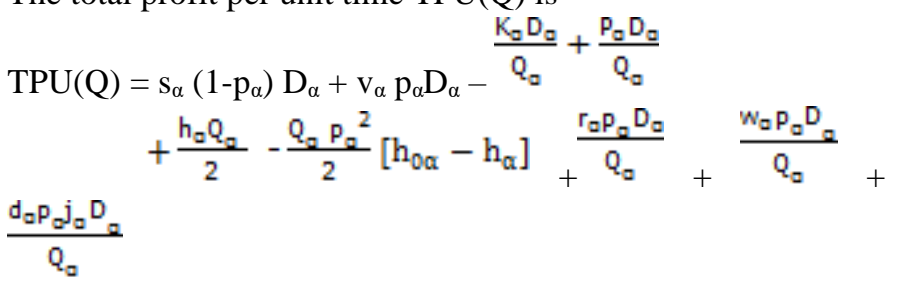

The expected aggregate profit per unit of time is

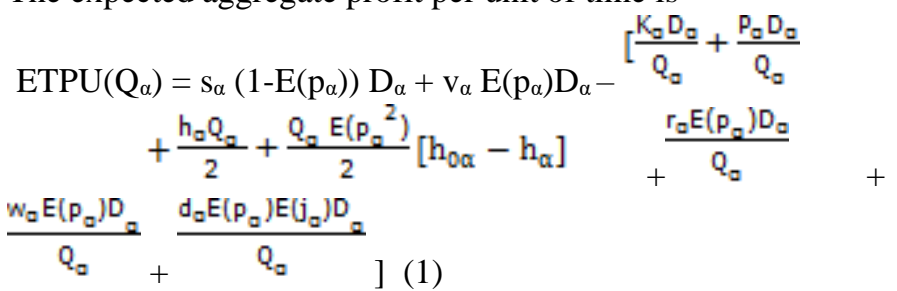

The value of $\mathrm{Q}_{\alpha}$ that maximizes the aggregate profit is $2 \mathrm{D}_{\mathrm{g}}\left(\mathrm{K}_{\mathrm{a}}+\mathrm{P}_{\mathrm{a}}+\mathrm{r}_{\mathrm{a}} \mathrm{E}\left(\mathrm{P}_{\mathrm{a}}\right]+\mathrm{W}_{\mathrm{a}} \mathrm{E}\left(\mathrm{P}_{\mathrm{a}}\right)+\mathrm{d}_{\mathrm{a}} \mathrm{E}\left(\mathrm{P}_{\mathrm{a}}\right) \mathrm{E}\left[\mathrm{j}_{\mathrm{g}}\right)\right.$

$\sqrt{h_{a}+E\left(P_{a}{ }^{2}\left[h_{0 a}-h_{a}\right]\right.}$

\section{Validation of the Model}

An inventory system with instant replenishment of stock of Q units is considered. The proposed model is validated by a numerical example comprising of the following inputs.

\begin{tabular}{|l|l|l|l|}
\hline Parameter & $\mathbf{X}$ & $\mathbf{Y}$ & $\mathbf{Z}$ \\
\hline Demand & 50,000 units/year & 50,000 units/ year & 50,000 units/ year \\
\hline Ordering cost & $200 /$ cycle & $200 /$ cycle & $200 /$ cycle \\
\hline $\begin{array}{l}\text { Holding cost for } \\
\text { maximum stock }\end{array}$ & $5 /$ unit/year & $4 /$ unit/year & $6 /$ unit/year \\
\hline
\end{tabular}




\begin{tabular}{|l|l|l|l|}
\hline $\begin{array}{l}\text { Holding cost for special } \\
\text { inventory }\end{array}$ & $6 /$ unit/year & $7 /$ unit/year & $8 /$ unit/year \\
\hline $\begin{array}{l}\text { Selling price of items in } \\
\text { maximum stock }\end{array}$ & $50 /$ unit & $60 /$ unit & $55 /$ unit \\
\hline $\begin{array}{l}\text { Selling price of items in } \\
\text { overage }\end{array}$ & $35 /$ unit & $40 /$ unit & $35 /$ unit \\
\hline $\begin{array}{l}\text { renovating cost of an } \\
\text { overage item }\end{array}$ & $5 /$ item & $6 /$ item & $5 /$ item \\
\hline $\begin{array}{l}\text { weeding cost of the } \\
\text { overage items }\end{array}$ & $2 /$ unit & $2 /$ unit & $2 /$ unit \\
\hline $\begin{array}{l}\text { waste disposal cost of the } \\
\text { items }\end{array}$ & $3 /$ unit & $3 /$ unit & $3 /$ unit \\
\hline Product propagation costs & $300 /$ cycle & $300 /$ cycle & $300 /$ cycle \\
\hline
\end{tabular}

We assume that $p_{\alpha}$ and $j_{\alpha}$, are uniformly distributed with its p.d.f as

$$
\begin{aligned}
& \mathrm{f}\left(\mathrm{p}_{\alpha}\right)=\left\{\begin{array}{c}
4,0 \leq p_{\alpha} \leq 0.25 \\
0, \text { otherwise }
\end{array} \quad \mathrm{f}\left(\mathrm{j}_{\alpha}\right)=\left\{\begin{array}{c}
20,0 \leq j_{\alpha} \leq 0.05 \\
0, \text { otherwise }
\end{array}\right.\right. \\
& \mathrm{E}\left(\mathrm{p}_{\alpha}\right)=0.125,{ }^{E\left(p_{\alpha}{ }^{2}\right)}=0.021 \quad, \mathrm{E}\left(\mathrm{j}_{\alpha}\right)=0.1
\end{aligned}
$$

Table 3.1. Results

\begin{tabular}{|l|l|l|}
\hline Items & $\begin{array}{l}\text { Optimal order } \\
\text { Quantity }\end{array}$ & $\begin{array}{l}\text { Expected Maximum } \\
\text { profit per unit of time }\end{array}$ \\
\hline $\mathrm{X}$ & $\mathrm{Q}_{\mathrm{X}}=3159$ & $\begin{array}{l}\mathrm{ETPU}\left(\mathrm{Q}_{\mathrm{X}}\right) \\
=2390390.991\end{array}$ \\
\hline $\mathrm{Y}$ & $\mathrm{Q}_{\mathrm{Y}}=3512$ & $\begin{array}{l}\mathrm{ETPU}\left(\mathrm{Q}_{\mathrm{Y}}\right) \\
=2859049.902\end{array}$ \\
\hline $\mathrm{Z}$ & $\mathrm{Q}_{\mathrm{Z}}=2879$ & $\begin{array}{l}\mathrm{ETPU}\left(\mathrm{Q}_{\mathrm{Z}}\right) \\
=2609057.656\end{array}$ \\
\hline
\end{tabular}

\section{Results and Discussion}

The expected aggregate profit per unit of time (1) is the difference between the aggregate incomes and expenses per cycle. The optimal order quantity of the items $X$, $\mathrm{Y}$ and $\mathrm{Z}$ (2) which maximizes the respective expected aggregate profit per unit of time is determined and presented in Table 3.1. The optimal order quantity $\mathrm{Q}_{\alpha}$ of each of the item and the respective expected maximum profit per unit of time is calculated. The costs of renovating and weeding of the overage items together with disposal and product propagation costs are also included in the aggregate expenses. This model reflects the total costs and revenue associated with overage management. The accumulation of the inventory is indeed a serious trouble to the production sectors and this model duly assists in handling the overage.

If the percentage of inventory that adds to overage is nil then the proposed model gets restored to the fundamental economic order quantity model. This model can be discussed in different environment, in the proposed model the nature of the demand pattern is deterministic. This model can be extended by changing the pattern of demand into linear, quadratic or exponential representing the scale of demand that varies from one production sector to another. This model is not specified to any kind of manufacturing firms as this encompasses the general costs parameters involved in handling overage inventory. The inclusion of the environmental costs is representing the social significance of the model in promoting the environmental sustainability, the additional inclusion of environmental costs will make the model accommodative of the techniques of environmental accounting.

This model also focuses on the key aspects of customer acquisition by including the costs of product propagation. This model discloses various channels of extending the model in different dimensions. The costs parameters included in the profit maximization inventory model can be classified as product related costs, environment costs and product propagation costs and this model presents a general picture of these cost parameters that could be explored or refined with the inclusion of different related costs. This model is underlying in nature and it will support in formulating further models based on overage with the inclusion of different costs parameters.

\section{Conclusion}

COVID-19, a pandemic outbreak in this digital era is a new kind of experience to many races of mankind. The mighty nations are losing its stamina in its battle against this dreadful 
health catastrophe and the final combating weapon in their hands is 'Social Distancing', an outrageous medication. The onset of quarantine has highly shattered the production sectors. The sudden interruption of curfew has disturbed the flow of product production and this pandemic impact on production has resulted in overage. A more generalized overage model is formulated in this research work to combat the situations of overage at times of pandemic outbreak. In this article the impacts of COVID 19 social distancing are briefly discussed. This model deals with the restoration of overage of multi items to maximum stock level. The proposed maximization model will certainly assist the decision makers to handle the situations of overage caused by pandemic social distancing. The model can be extended to fuzzy models by changing the nature of the demand and costs also the concept of fuzzy probability functions can be applied to overcome the obstacles of uncertainty. The model can also be validated with concrete illustrations.

This model has wide range of scope in framing production policies by the industries to meet the pandemic situations and other unexpected calamities that disrupt the production process. This research work is of exploratory kind and the proposed model can be discussed and extended by incorporating various costs parameters reflecting the various stages and steps involved in the production processes.

\section{REFERENCES}

[1]. Deshmukh, S.G., Haleem, A.(2020). Framework for Manufacturing in Post-COVID-19 World Order: An Indian Perspective. JGBC 15, 49-60.

[2]. Naveen Donthu.,Anders Gustafsson(2020). Effects of COVID-19 on business and research, Journal of Business Research ,vol.117,pp 284-289

[3]. Unhale, Shrikrushna \& Bilal, Quazi \& Sanap, Shubham \& Thakhre, Suraj \& Wadatkar, Shreya \& Bairagi, Rohit \& Sagrule, Prof \& Biyani, Dr. (2020). A review on corona virus (COVID-19). International Journal of Pharmaceutical and Life Sciences. 6. 109 - 115.

[4]. Yan-Rong Guo1, Qing-Dong Cao , Zhong-Si Hong , Yuan-Yang Tan, Shou-Deng Chen, Hong-Jun Jin , Kai-Sen Tan, De-Yun Wang, Yan Yan (2020) The origin, transmission and clinical therapies on coronavirus disease 2019 (COVID-19) outbreakAn update on the status, Guo et al. Military Medical Research 7:11.1-10.

[5]. Poudel, Padam \& Poudel, M.R. \& Gautam, Aasish \& Phuyal, Samiksha \& Tiwari, Chiran \& Bashyal, Nisha \& Bashyal, Shila. (2020). COVID-19 and its Global Impact on Food and Agriculture. 10.35248/2322-3308.20.09.221

[6]. Kumar, Sunil. (2020). Impact of coronavirus (COVID-19) on Indian economy.
[7]. Geoff Relph., (2003), "Overage inventory-how does it occur and why is it important?", International Journal Production Economics,Vol.81-82,pp. 163-171.

[8]. Ritha.W.,Jayanthi.K (2019), "Determination of Fuzzy Total Profit of the Enterprise which channelizes the Overage to Customer Acquisition", International Journal of Research in Advent Technology (IJRAT) Special Issue, January 2019

[9]. Elham Ahmadzadeh., Behnam Vahdani., (2017), “A location-inventory-pricing model in a closed loop supply chain network with correlated demands and shortages under a periodic review system", Computers \& Chemical Engineering, Vol. 1019,pp148-166.

[10]. Alejandro Vital Soto., Nusrat T. Chowdhury., Maral Z. Allahyari., Ahmed Azab., Mohammed F. Baki., (2017), "Mathematical modeling and hybridized evolutionary LP local search method for lot-sizing with supplier selection, inventory shortage, and quantity discounts", Computers \& Industrial Engineering Vol. 109, pp 96-112.

[11]. Swati Agrawal., Snigdha Banerjee., Sotirios Papachristos., (2013), "Inventory model with deteriorating items, ramp-type demand and partially backlogged shortages for a two warehouse system", Applied Mathematical Modelling, Vo 37, Issues 20-211 pp.8912-8929.

[12]. Umakanta Mishra., Jei-Zheng Wu., Biswajit Sarkar.,(2020), “A sustainable production-inventory model for a controllable carbon emissions rate under shortages", Journal of Cleaner Production, Vol. 256, pp.1-24.

[13]. Harris, F. (1913), "How many parts to make at once, factory", The Magazine of Management, Vol.2 pp.135-136.

[14]. Taft.E.W.(1918), “The Most Economical Production Lot," The Iron Age, Vol. 101, pp. 1410 1412.

[15]. http://14.139.186.108/jspui/bitstream/12345 6789/31136/1/Nivetha_Martin_Thesis.pdf 